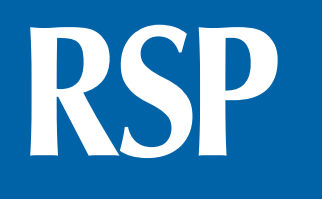

http://www.rsp.fsp.usp.br/
Revista de Saúde Pública

\title{
Predictive model of unfavorable outcomes for multidrug-resistant tuberculosis
}

\author{
Luiz Henrique Arroyo' (iD), Antônio Carlos Vieira Ramos' (iD, Mellina Yamamura' (iD), Thais Zamboni \\ Berra' (iD), Luana Seles Alves' (iD), Aylana de Souza Belchior' (iD), Danielle Talita Santos' (iD), Josilene \\ Dália Alves' iD, Laura Terenciani Campoy' iD, Marcos Augusto Moraes Arcoverde' iD, Valdes \\ Roberto Bollela" iD, Sidney Bombarda"I iD, Carla Nunes ${ }^{\mathrm{IV}}$ iD, Ricardo Alexandre Arcêncio' iD \\ I Universidade de São Paulo. Escola de Enfermagem de Ribeirão Preto. Ribeirão Preto, SP, Brasil \\ " Universidade de São Paulo. Faculdade de Medicina de Ribeirão Preto. Ribeirão Preto, SP, Brasil \\ III Secretaria de Estado da Saúde de São Paulo. São Paulo, SP, Brasil \\ Iv Universidade NOVA de Lisboa. Escola Nacional de Saúde Pública. Lisboa, Portugal
}

\section{ABSTRACT}

OBJECTIVE: to analyze the temporal trend, identify the factors related and elaborate a predictive model for unfavorable treatment outcomes for multidrug-resistant tuberculosis (MDR-TB).

METHODS: Retrospective cohort study with all cases diagnosed with MDR-TB between the years 2006 and 2015 in the state of São Paulo. The data were collected from the state system of TB cases notifications (TB-WEB). The temporal trend analyzes of treatment outcomes was performed through the Prais-Winsten analysis. In order to verify the factors related to the unfavorable outcomes, abandonment, death with basic cause TB and treatment failure, the binary logistic regression was used. Pictorial representations of the factors related to treatment outcome and their prognostic capacity through the nomogram were elaborated.

RESULTS: Both abandonment and death have a constant temporal tendency, whereas the failure showed it as decreasing. Regarding the risk factors for such outcomes, using illicit drugs doubled the odds for abandonment and death. Besides that, being diagnosed in emergency units or during hospitalizations was a risk factor for death. On the contrary, having previous multidrug-resistant treatments reduced the odds for the analyzed outcomes by $33 \%$. The nomogram presented a predictive model with $65 \%$ accuracy for dropouts, $70 \%$ for deaths and $80 \%$ for failure.

CONCLUSIONS: The modification of the current model of care is an essential factor for the prevention of unfavorable outcomes. Through predictive models, as presented in this study, it is possible to develop patient-centered actions, considering their risk factors and increasing the chances for cure.

DESCRIPTORS: Tuberculosis, Multidrug-Resistant, complications. Tuberculosis, Multidrug-Resistant, mortality. Risk Factors. Treatment Adherence and Compliance. 


\section{INTRODUCTION}

Multidrug-resistant tuberculosis (MDR-TB) is considered a global public health problem and a major threat to the control and elimination of tuberculosis (TB) in the world. Characterized by a bacillus resistant to isoniazid and rifampicin, two of the main drugs in the initial treatment regimen, it is estimated that MDR-TB in 2016 reported about 490,000 cases, equivalent to $4.7 \%$ of the total number of people who became ill from $\mathrm{TB}$ in the world ${ }^{1}$.

According to the latest report by the World Health Organization (WHO), 54\% of cases started treatment for MDR-TB in 2014, 54\% have successfully completed it (cure or complete treatment), $15 \%$ have lost to follow-up, $8 \%$ had some kind of failure, and $16 \%$ died. Comparing the outcomes of new cases or recurrences of TB in which the bacillus is sensitive to first-line drugs, there was an $83 \%$ cure, indicating that increasing success rates in MDR-TB treatment is one of the major global challenges for disease control' ${ }^{1}$.

The difficulty of success is a consequence of the insufficiency of therapies that allow to coordinate treatments more effective and with greater capacity for the favorable outcome. Treatment regimens are still based on fragile scientific evidence, and drugs used do not always undergo randomized controlled trials, which results in a high frequency of treatment failures ${ }^{2}$.

In addition, long periods of exposure to drugs with high toxicity that can trigger serious adverse effects, coupled with treatments that raise catastrophic household expenditures, social stigma and psychological stress, reduce adherence and tolerance of patients to the MDR-TB treatment and increase the risk for unfavorable outcomes such as death, abandonment and treatment failure ${ }^{3,4}$.

Despite this, the country has low rates of cure for MDR-TB treatment, reaching only $61.4 \%$, a percentage below that established by $\mathrm{WHO}(75 \%)^{1}$. Thus, it is imperative to identify the barriers that prevent the cure of patients, under penalty of the transmission of resistant Mycobacterium tuberculosis, which contributes to the increase of the proportion of MDR-TB between incident of TB cases and the development of forms of the disease, such as extensively resistant tuberculosis (XDR-TB) ${ }^{5}$.

Thus, considering the complexity involved in the success of MDR-TB treatment and the lack of research on the subject, this study aims to characterize the outcomes of MDR-TB treatment and to analyze the temporal trend and factors related to unfavorable outcomes in the state of Sao Paulo.

\section{METHODS}

\section{Study design and population}

Retrospective cohort study using secondary data from the state TB case notification system, TBWeb. All cases diagnosed with MDR-TB between the years 2006 and 2015 were used in the 645 municipalities of the state of São Paulo. The data were collected at the Center for Epidemiological Surveillance Prof. Alexandre Vranjac in December 2017.

\section{Variables and statistical analysis}

Initially, in the exploratory approach of the database the duplications were removed. In this process the full name of the individual, full name of the mother and date of birth were used, remaining for the analyzes only the most current outcome.

The descriptive analysis considered the number of previous treatments for MDR-TB and the individual characteristics present in TBWeb's case report form: sociodemographic 
(gender, age, ethnicity, schooling and type of address), clinical (clinical form of MDR-TB and associated comorbidities) and operational (way of discovering the case and supervised or self-administered treatment). It is worth noting that unfavorable outcomes were those cases whose last closure was death, abandonment and treatment failure.

The unfavorable outcomes in the treatment of MDR-TB are established by the National Program for the Control of Tuberculosis (PNCTB) as treatments that evolve negatively and result in dropouts, treatment failure or deaths. Abandonment is defined as not taking the medication for more than 30 consecutive days. Treatment failure is defined by two or more positive cultures after the 12th month of treatment or according to the assessment of the patients' clinical status ${ }^{6}$.

Then, the annual occurrence of each outcome was verified, including all types available for completion in the notification form (cure, abandonment, treatment failure, TB death, non-TB death, other outcomes, without outcome information). Subsequently, analyzes of temporal trends (temporal regression), whose predictive variables were the number of cure outcomes, abandonment, treatment failure, death with basic TB cause and death without basic TB cause, and the response variable was time (in years).

The outcomes were logarithmized, reducing the heterogeneity of the residue variance in the time regression. This time trend was performed using the self-reported analysis method known as Prais-Winsten, whose result is called the annual increase rate, with a $95 \%$ confidence interval $(95 \% \mathrm{CI})$. Significant results could represent the annual increase or decrease in the occurrence of outcomes, while non-significant outcomes may be considered stationary ${ }^{7}$.

To verify the factors related to the unfavorable outcomes, binary logistic regression was used, having as reference the treatments with cure, and as independent variables the individual information of the patients. It should be emphasized that different models were used for each of the outcomes.

In the first step, the crude odds ratio (OR) with $95 \%$ CI was calculated. Subsequently, the variables with significant OR were included in the multiple model with the forward method (likelihood ratio), determining their adjusted odds ratio (ORaj). For both final models, the determination of pseudocofficients $\left(\right.$ McFadden $\mathrm{R}^{2}$ ), Wald statistic and prediction or accuracy of the models were calculated using the area below the characteristic curve of the receiver operating characteristic (ROC) and its values of 95\%CI. The values of the ROC curve were interpreted according to Šimundić ${ }^{8}$.

Pictorial representations of the factors related to death, abandonment and failure in the treatment of MDR-TB and its prognostic capacity for the outcomes in the form of probabilities were made. Such a technique is called nomogram and is presented as a scoring scale for each variable introduced in the analysis. This score is equivalent to a certain probability for the event being studied, in this case, treatment outcomes 9 .

\section{Ethical Aspects}

The study was approved by the Research Ethics Committee of the University of São Paulo at School of Nursing of Ribeirão Preto on September 12, 2017, with an Ethics Presentation Certificate (CAAE) protocol number 71051017.8.0000.5393.

\section{RESULTS}

A total of 1,168 MDR-TB reports were identified in the state of São Paulo from 2006 to 2015. After filtering the duplicate reports, the total number of 802 patients affected by the disease was verified. Their sociodemographic and clinical-operational characteristics are presented in Table 1. 
Table 1. Profile of 802 cases of multidrug-resistant tuberculosis reported in the state of São Paulo from 2006 to 2015.

\begin{tabular}{|c|c|c|}
\hline Variable & $\mathbf{n}$ & $\%$ \\
\hline \multicolumn{3}{|l|}{ Outcome of treatments } \\
\hline Cure & 323 & 40.3 \\
\hline Abandonment & 66 & 8.2 \\
\hline Treatment failure & 275 & 34.3 \\
\hline Change of diagnosis & 6 & 0.7 \\
\hline Non-tuberculosis death & 55 & 6.8 \\
\hline Death due to tuberculosis & 56 & 7.0 \\
\hline Transfer & 5 & 0.7 \\
\hline No information & 16 & 2.0 \\
\hline \multicolumn{3}{|l|}{ No. of treatments } \\
\hline One treatment & 522 & 65.1 \\
\hline More than one treatment & 280 & 34.9 \\
\hline \multicolumn{3}{|l|}{ Ethnicity } \\
\hline White & 358 & 44.6 \\
\hline Black/brown & 267 & 33.3 \\
\hline Others (yellow, indigenous) & 6 & 0.7 \\
\hline No information & 171 & 21.3 \\
\hline \multicolumn{3}{|l|}{ Age (years old) } \\
\hline$\leq 14$ & 7 & 0.9 \\
\hline $15-29$ & 197 & 24.5 \\
\hline $30-59$ & 532 & 66.3 \\
\hline$\geq 60$ & 66 & 8.2 \\
\hline \multicolumn{3}{|l|}{ Gender } \\
\hline Male & 564 & 70.3 \\
\hline Female & 238 & 29.7 \\
\hline \multicolumn{3}{|l|}{ Education level } \\
\hline$\leq 7$ years & 354 & 44.1 \\
\hline$>7$ years & 311 & 38.8 \\
\hline No information & 137 & 17.1 \\
\hline \multicolumn{3}{|l|}{ Clinical Form } \\
\hline Pulmonary & 782 & 97.5 \\
\hline Extrapulmonary & 20 & 2.5 \\
\hline \multicolumn{3}{|l|}{ Way of discovering } \\
\hline Outpatient demand & 531 & 66.2 \\
\hline Urgency/emergency or during hospital stay & 205 & 25.6 \\
\hline Active case search & 38 & 4.7 \\
\hline No information & 28 & 3.5 \\
\hline \multicolumn{3}{|l|}{ HIV Testing } \\
\hline Executed & 735 & 91.6 \\
\hline Unexecuted & 67 & 8.4 \\
\hline \multicolumn{3}{|l|}{ AIDS } \\
\hline Yes & 104 & 13.0 \\
\hline No & 621 & 77.4 \\
\hline No information* & 77 & 9.6 \\
\hline \multicolumn{3}{|l|}{ Diabetes } \\
\hline Yes & 103 & 12.8 \\
\hline No & 699 & 87.2 \\
\hline
\end{tabular}




\begin{tabular}{|c|c|c|}
\hline \multicolumn{3}{|l|}{ Continuation } \\
\hline \multicolumn{3}{|l|}{ Alcoholism } \\
\hline Yes & 183 & 22.8 \\
\hline No & 619 & 77.2 \\
\hline \multicolumn{3}{|l|}{ Mental illness } \\
\hline Yes & 12 & 1.5 \\
\hline No & 790 & 98.5 \\
\hline \multicolumn{3}{|l|}{ Use of illicit drugs } \\
\hline Yes & 96 & 12.0 \\
\hline No & 706 & 88.0 \\
\hline \multicolumn{3}{|l|}{ Smoking } \\
\hline Yes & 70 & 8.7 \\
\hline No & 732 & 91.3 \\
\hline \multicolumn{3}{|l|}{ Type of address } \\
\hline Default Address & 742 & 92.5 \\
\hline Prisoner & 44 & 5.5 \\
\hline Without fixed residence & 16 & 3.0 \\
\hline \multicolumn{3}{|l|}{ Treatment type } \\
\hline Supervised & 663 & 76.5 \\
\hline Self-administered & 154 & 17.7 \\
\hline No Information & 50 & 5.8 \\
\hline
\end{tabular}

* 10 cases with HIV positive test but not classified with AIDS were considered without information.

Table 2. Distribution of treatment outcomes by year and temporal trend, São Paulo, 2006-2015.

\begin{tabular}{|c|c|c|c|c|c|c|c|c|c|c|c|c|c|c|}
\hline \multirow{2}{*}{ Outcome } & \multirow{2}{*}{$\frac{2006}{\mathrm{n}(\%)}$} & \multirow{2}{*}{$\frac{2007}{n(\%)}$} & \multirow{2}{*}{$\frac{2008}{n(\%)}$} & \multirow{2}{*}{$\frac{2009}{n(\%)}$} & \multirow{2}{*}{$\frac{2010}{\mathrm{n}(\%)}$} & \multirow{2}{*}{$\frac{2011}{n(\%)}$} & \multirow{2}{*}{$\frac{2012}{n(\%)}$} & \multirow{2}{*}{$\frac{2013}{n(\%)}$} & \multirow{2}{*}{$\frac{2014}{n(\%)}$} & \multirow{2}{*}{$\frac{2015}{\text { n (\%) }}$} & \multirow{2}{*}{ Total } & \multirow{2}{*}{ Coefficient } & \multirow{2}{*}{$95 \% \mathrm{Cl}$} & \multirow{2}{*}{$\begin{array}{c}\text { Temporal } \\
\text { trend }\end{array}$} \\
\hline & & & & & & & & & & & & & & \\
\hline Cure & $\begin{array}{c}28 \\
(34.57)\end{array}$ & $\begin{array}{c}18 \\
(26.87)\end{array}$ & $\begin{array}{c}20 \\
(29.85)\end{array}$ & $\begin{array}{c}14 \\
(14.58)\end{array}$ & $\begin{array}{c}20.00 \\
(22.99)\end{array}$ & $\begin{array}{c}47 \\
(50.54)\end{array}$ & $\begin{array}{c}42 \\
(54.55)\end{array}$ & $\begin{array}{c}33 \\
(55.93)\end{array}$ & $\begin{array}{c}44 \\
(55.70)\end{array}$ & $\begin{array}{c}57 \\
(59.38)\end{array}$ & $\begin{array}{c}323 \\
(40.27)\end{array}$ & 0.05 & $0.01-0.09$ & Increasing \\
\hline Abandonment & $\begin{array}{c}4 \\
(4.94)\end{array}$ & $\begin{array}{c}4 \\
(5.97)\end{array}$ & $\begin{array}{c}7 \\
(10.45)\end{array}$ & $\begin{array}{c}12 \\
(12.50)\end{array}$ & $\begin{array}{c}5.00 \\
(5.75)\end{array}$ & $\begin{array}{c}4 \\
(4.30)\end{array}$ & $\begin{array}{c}5 \\
(6.49)\end{array}$ & $\begin{array}{c}6 \\
(10.17)\end{array}$ & $\begin{array}{c}7 \\
(8.86)\end{array}$ & $\begin{array}{c}12 \\
(12.50)\end{array}$ & $\begin{array}{c}66 \\
(8.23)\end{array}$ & 0.03 & $-0.02-0.08$ & Stationary \\
\hline $\begin{array}{l}\text { Treatment } \\
\text { failure }\end{array}$ & $\begin{array}{c}37 \\
(45.68)\end{array}$ & $\begin{array}{c}34 \\
(50.75)\end{array}$ & $\begin{array}{c}33 \\
(49.25)\end{array}$ & $\begin{array}{c}52 \\
(54.17)\end{array}$ & $\begin{array}{l}42.00 \\
(48.28)\end{array}$ & $\begin{array}{c}30 \\
(32.26)\end{array}$ & $\begin{array}{c}17 \\
(22.08)\end{array}$ & $\begin{array}{c}12 \\
(20.34)\end{array}$ & $\begin{array}{c}11 \\
(13.92)\end{array}$ & $\begin{array}{c}7 \\
(7.29)\end{array}$ & $\begin{array}{c}275 \\
(34.29)\end{array}$ & -0.08 & $-0.01--0.02$ & Decreasing \\
\hline Death TB & $\begin{array}{c}3 \\
(3.70)\end{array}$ & $\begin{array}{c}7 \\
(10.45)\end{array}$ & $\begin{array}{c}1 \\
(1.49)\end{array}$ & $\begin{array}{c}8 \\
(8.33)\end{array}$ & $\begin{array}{c}8 \\
(9.19)\end{array}$ & $\begin{array}{c}4 \\
(4.30)\end{array}$ & $\begin{array}{c}5 \\
(6.49)\end{array}$ & $\begin{array}{c}5 \\
(8.47)\end{array}$ & $\begin{array}{c}7 \\
(8.86)\end{array}$ & $\begin{array}{c}8 \\
(8.33)\end{array}$ & $\begin{array}{c}56 \\
(6.98)\end{array}$ & 0.03 & $-0.01-0.08$ & Stationary \\
\hline Death not TB & $\begin{array}{c}6 \\
(7.41)\end{array}$ & $\begin{array}{c}2 \\
(2.98)\end{array}$ & $\begin{array}{c}4 \\
(5.97)\end{array}$ & $\begin{array}{c}9 \\
(9.37)\end{array}$ & $\begin{array}{c}10 \\
(11.49)\end{array}$ & $\begin{array}{c}5 \\
(5.38)\end{array}$ & $\begin{array}{c}7 \\
(9.09)\end{array}$ & $\begin{array}{c}3 \\
(5.08)\end{array}$ & $\begin{array}{c}6 \\
(7.59)\end{array}$ & $\begin{array}{c}3 \\
(3.12)\end{array}$ & $\begin{array}{c}55 \\
(6.86)\end{array}$ & -0.01 & $-0.06-0.05$ & Stationary \\
\hline Other & $\begin{array}{c}2 \\
(2.47)\end{array}$ & $\begin{array}{c}1 \\
(1.49)\end{array}$ & $\begin{array}{c}0 \\
(0)\end{array}$ & $\begin{array}{c}0 \\
(0.00)\end{array}$ & $\begin{array}{c}2 \\
(2.30)\end{array}$ & $\begin{array}{c}2 \\
(2.15)\end{array}$ & $\begin{array}{c}1 \\
(1.30)\end{array}$ & $\begin{array}{c}0 \\
(0)\end{array}$ & $\begin{array}{c}1 \\
(1.27)\end{array}$ & $\begin{array}{c}2 \\
(2.08)\end{array}$ & $\begin{array}{c}11 \\
(1.38)\end{array}$ & - & - & - \\
\hline No Information & $\begin{array}{c}1 \\
(1.23) \\
\end{array}$ & $\begin{array}{c}1 \\
(1.49)\end{array}$ & $\begin{array}{c}2 \\
(2.99) \\
\end{array}$ & $\begin{array}{c}1 \\
(1.04) \\
\end{array}$ & $\begin{array}{c}0 \\
(0)\end{array}$ & $\begin{array}{c}1 \\
(1.08)\end{array}$ & $\begin{array}{c}0 \\
(0.00)\end{array}$ & $\begin{array}{c}0 \\
(0)\end{array}$ & $\begin{array}{c}3 \\
(3.80) \\
\end{array}$ & $\begin{array}{c}7 \\
(7.29)\end{array}$ & $\begin{array}{c}16 \\
(1.99)\end{array}$ & - & - & - \\
\hline Total & $\begin{array}{c}81 \\
(10.10)\end{array}$ & $\begin{array}{c}67 \\
(8.35)\end{array}$ & $\begin{array}{c}67 \\
(8.35)\end{array}$ & $\begin{array}{c}96 \\
(11.97)\end{array}$ & $\begin{array}{c}87 \\
(10.85)\end{array}$ & $\begin{array}{c}93 \\
(11.60)\end{array}$ & $\begin{array}{c}77 \\
(9.60)\end{array}$ & $\begin{array}{c}59 \\
(7.36)\end{array}$ & $\begin{array}{c}79 \\
(9.85)\end{array}$ & $\begin{array}{c}96 \\
(11.97)\end{array}$ & $\begin{array}{c}802 \\
(100)\end{array}$ & $<0.01$ & $-0.01-0.02$ & Stationary \\
\hline
\end{tabular}

TB: tuberculosis

Cure was the treatment outcome with the highest prevalence $(\mathrm{n}=323,40.3 \%)$; however, treatment failure was almost as frequent, with 275 (34.3\%) occurrences. Other unfavorable outcomes, such as abandonment and death with a basic TB cause, occurred in $15.2 \%(\mathrm{n}=122)$ of the cases. Despite the predominance of patients undergoing only one treatment, $34.9 \%$ $(\mathrm{n}=280)$ had previously been treated for MDR-TB.

Regarding the sociodemographic profile, there were predominant cases of males, aged between 15 and 59 years, white and with less than seven years of schooling. Concerning the clinical-operational characteristics, the pulmonary form of the disease prevailed and the diagnosis was made in general by outpatient demands; however, a quarter of the cases were found in emergency services or during hospital stay $(n=205,25.6 \%)$. 
Table 3. Results of the logistic regression for the abandonment, death by tuberculosis and treatment failure, with class of cure reference, in the treatment of multidrug-resistant tuberculosis, São Paulo, 2006-2015.

\begin{tabular}{|c|c|c|c|c|c|c|}
\hline \multirow{2}{*}{ Explanatory variables } & \multicolumn{2}{|c|}{ Cure/abandonment } & \multicolumn{2}{|c|}{ Death due to tuberculosis } & \multicolumn{2}{|c|}{ Cure/treatment failure } \\
\hline & OR $(95 \% \mathrm{Cl})$ & ORaj (IC $95 \%)^{1}$ & OR $(95 \% \mathrm{Cl})$ & ORaj $($ IC95\%) & OR $(95 \% \mathrm{Cl})$ & ORaj $($ IC95\%) \\
\hline
\end{tabular}

Number of previous MDR

treatments

$\begin{array}{lcccccc}\text { None } & 1 & 1 & 1 & 1 & 1 & 1 \\ \text { One or more } & 0.37(0.18-0.72) & 0.33(0.16-0.66) & 0.38(0.17-0.79) & 0.41(0.18-0.90) & 0.05(0.03-0.10) & 0.06(0.03-0.11)\end{array}$

Race/color

White

Black/brown

1

Age (years old)

$\leq 40$

$>40$

$0.67(0.33-1.31)$

Gender $(\mathrm{n}=856)$

Male

1

Female

$0.79(0.37-1.60)$

1

$0.74(0.37-1.44)$

$1.16(0.55-2.40)$

1

$0.93(0.62-1.37)$

Education level

$$
\begin{aligned}
& \leq 7 \text { years } \\
& >7 \text { years }
\end{aligned}
$$

Clinical Form

Pulmonary

Extrapulmonary

$2.59(0.11-27.72)$

Outpatient demand and active search

Urgency/emergency or during hospital stay

$1.70(0.76-3.62)$

$3.36(1.53-7.24) \quad 2.88(1.28-6.33)$

$2.01(1.26-3.22)$

$1.20(0.69-2.11)$

HIV

\section{Negative}

Positive

1

$0.20(0.01-1.01)$

1

$0.25(0.01-1.26)$

1

Diabetes

$\begin{array}{cc}\text { No } & 1 \\ \text { Yes } & 1.54(0.56-5.40)\end{array}$

Alcoholism

No

Yes

1

$1.79(0.83-3.68)$

Mental illness

$\begin{array}{lc}\text { No } & 1 \\ \text { Yes } & 2.63(0.35-13.98)\end{array}$

Use of illicit drugs

No

Yes

$2.07(1.03-4.71)$

\section{1}

Smoking

No

1

Yes

$0.56(0.16-1.51)$

1

$1.02(0.22-3.29)$

1

$1.59(0.59-3.81)$

Self-administered

MDR: multidrug-resistant; OR: odds ratio; ORaj: adjusted odds ratio

a AIC: 222.47; pseudo R² (McFadden): 0.05; Wald: $F=5.87$ ( $<<0.01$ ); ROC: 0.65 (95\%Cl 0.57-0.73).

b AIC: 191.62; pseudo R2 (McFadden): 0.07; Wald: $F=4.81$ ( $<<0.01$ ); ROC: 0.70 (95\%Cl 0.61-0.79).

c AIC: 434.14; pseudo R2 (McFadden): 0.26; Wald: $F=26.48$ ( $p<0.01$ ); ROC: 0.80 (95\%Cl 0.76-0.84).

\section{1}

$0.83(0.56-1.22)$

$0.86(0.56-1.31)$

1

$0.89(0.60-1.31)$

$1.72(0.28-13.20)$

\section{1}

$1.59(0.59-3.83)$

1

$1.91(0.84-4.15)$

1

$1.59(0.08-11.22)$

1

1

$1.14(0.40-2.80)$

1

$0.83(0.12-3.14)$

1

$1.70(0.59-4.31)$
$1.62(1.25-4.10)$
1

$0.82(0.46-1.47)$

1

$0.93(0.57-1.50)$

\section{1}

$1.47(0.26-4.91)$

1

$0.85(0.45-1.60)$

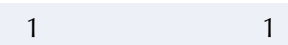

$0.35(0.17-0.68) \quad 0.52(0.23-1.14)$
$1.07(0.49-2.29)$

\author{
1
}

$2.34(1.37-4.09)$

$1.45(0.77-2.81)$
$0.54(0.25-1.09)$ 
None of the registered comorbidities showed to be more prevalent among the cases; however, the most frequent comorbidity was alcoholism, followed by HIV/AIDS and diabetes. Most of the registered patients had a standard address $(\mathrm{n}=742,92.5 \%)$, with individuals deprived of freedom forming $5.5 \%(n=44)$ of the cohort and the remainder representing persons without a fixed residence.

Observing treatment outcomes per year studied (Table 2), it can be seen that the average cure rate between 2006 and 2010 was $25.77 \%$ and $55.22 \%$ in subsequent years. Time trend analysis demonstrated the growth rate of cure at $5 \%$ per year. Failure in treatment was the predominant outcome among the first four years studied; however, after 2011 this percentage dropped, reaching only $7.29 \%$ in 2015 . In the interpretation of the time trend, this outcome decreased around $8 \%$ per year. In addition, $\mathrm{TB}$ abandonment and deaths remained practically constant in the observed years, which was confirmed by the steady tendency of the cases.

In the analysis of the factors associated with unfavorable outcomes in the studied cohort (Table 3), the crude OR values adjusted for death with basic TB cause, abandonment and treatment failure are presented. The history of one or more previous treatments of MDR-TB (ORaj $=0.33$, 95\%CI 0.16-0.66) was a protective factor for abandonment, while illicit drug use was a risk factor (ORaj $=2.56,95 \% \mathrm{CI} 1.02-6.12)$. The number of previous treatments was a protective factor for death (ORaj $=0.41,95 \%$ CI 0.18-0.90), while the associated risk factors were diagnosis in emergency services or during hospitalization (ORaj $=2.88$; 95\%CI 1.28-6.33) and illicit drug use $(\mathrm{ORaj}=2.06$; 95\%CI 1.36-5.59). Finally, the treatment failure outcome presented a protection association only with the number of treatments to which the patient was submitted (ORaj = 0.06; 95\% CI 0.03-0.11), similarly to the other unfavorable outcomes analyzed.

The logistic model for abandonment presented an area below the ROC curve of 0.65 (95\% CI 0.57-0.73), while the ROC value for the death model was 0.70 (95\%CI 0.61-0.79), and for treatment failure, 0.80 (95\%CI 0.76-0.84). The discrimination power of the model was classified as "sufficient" to identify the abandonment, "good" to point to death and "very good" for treatment failure. In addition, the diagnosis of the regression models indicated adequacy and non-violation of assumptions.

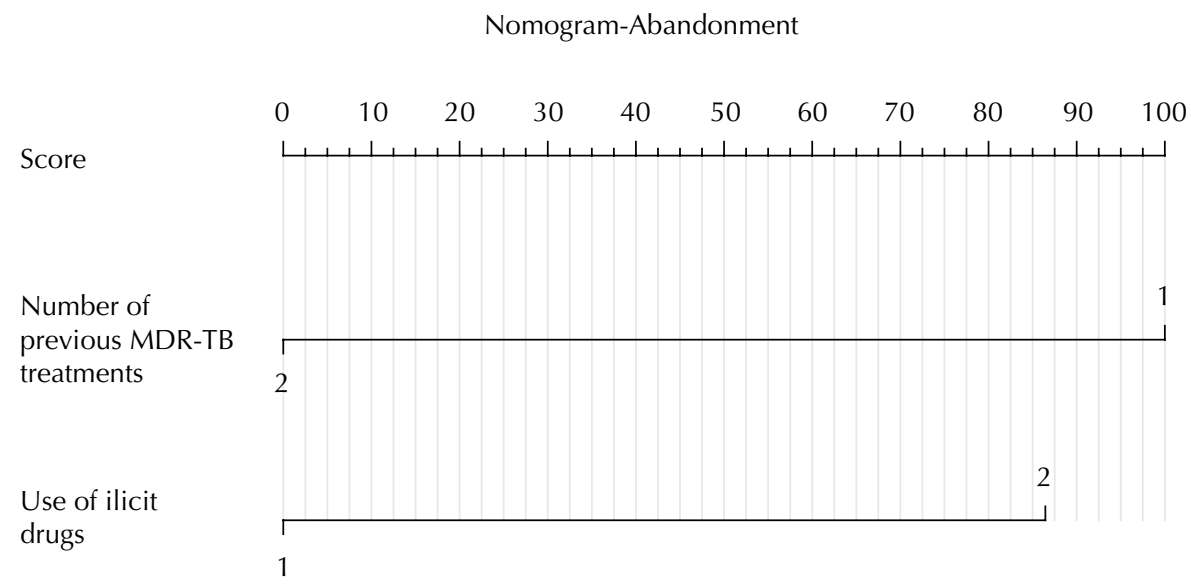

Total

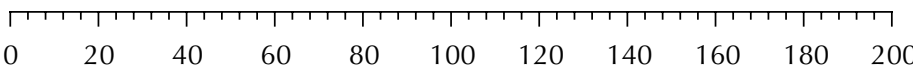

Probability

\begin{tabular}{|llllllll|l|}
\hline & & & & & & & \\
0.1 & 0.15 & 0.2 & 0.25 & 0.3 & 0.35 & 0.4 & 0.45
\end{tabular}

Number of previous MDR-TB treatments: (1) first treatment, (2) more than one treatment for MDR-TB; Use of illicit drugs: (1) patient does not use illicit drugs, (2) patient makes use of illicit drugs.

Figure 1. Nomograms of dropouts in the treatment of multidrug-resistant tuberculosis. 
The explanatory variables related to the unfavorable outcomes, as indicated in the binary logistic model, were analyzed using the nomogram, which predicts the probability that each characteristic has for abandonment (Figure 1), death and treatment failure (Figure 2). Depending on the individual aspects of the patient in relation to the inserted variables,

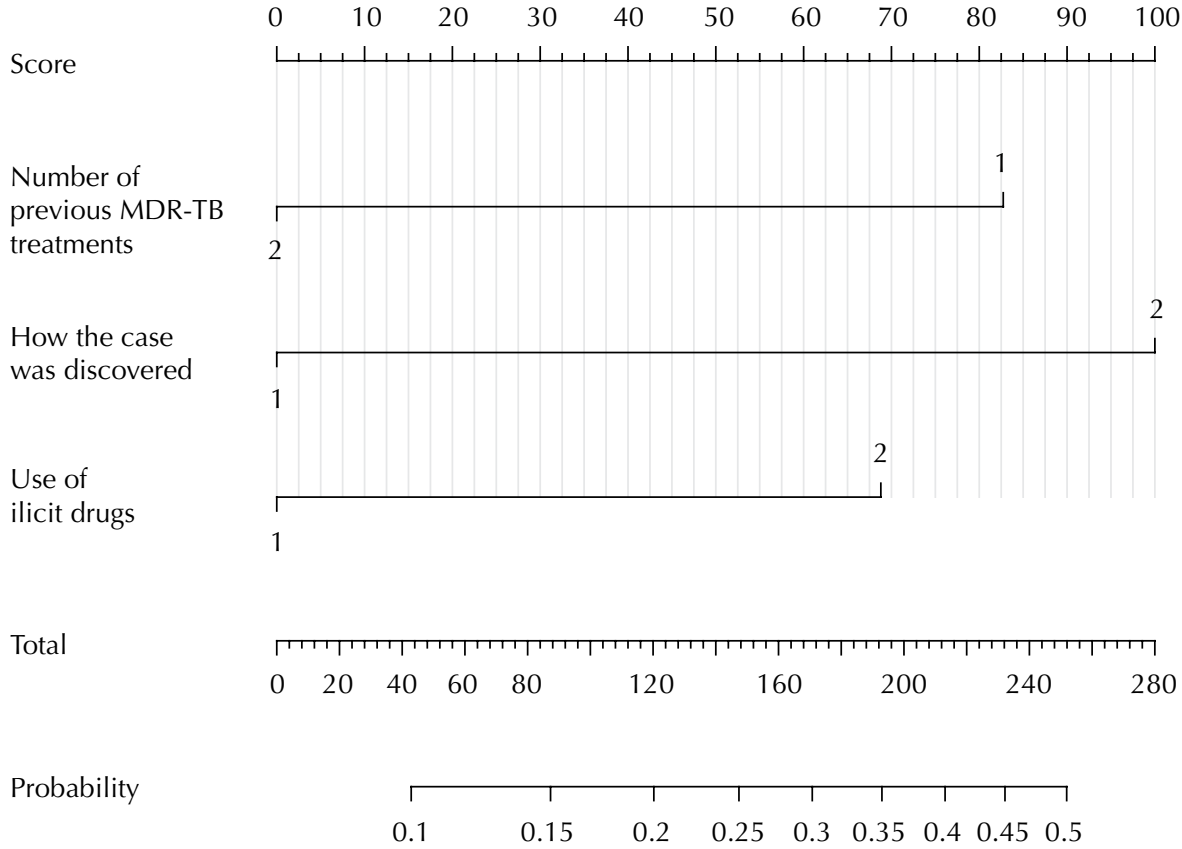

Nomogram-Treatment failure

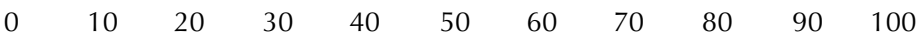

Score

$, 1,1,1,1,1,1,1,1,1,1,1,1,1,1,1,1,1,1,1,1,1,1,1,1$,

Number of
previous MDR-TB
treatments
How the case
was discovered
Smoking
Treatment type
Total
Probability

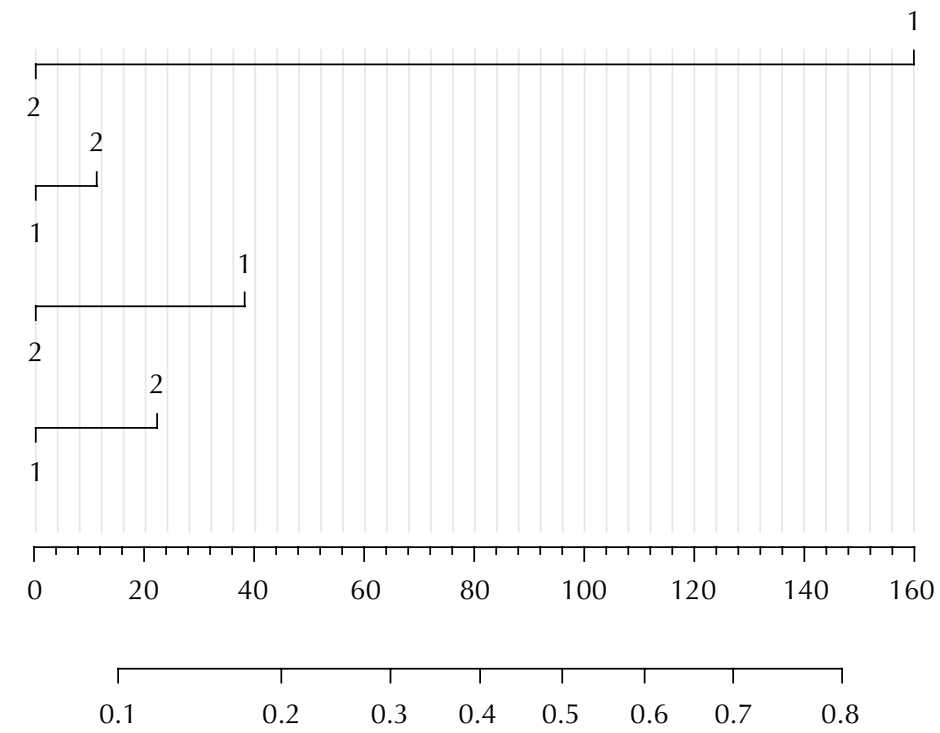

Number of previous MDR-TB treatments: - (1): first treatment; (2) more than one treatment for MDR-TB; Form of discovery of the case: (1) diagnosis by outpatient demand and active search of the cases; (2) diagnosis in emergency service and during hospitalization. Use of illicit drugs: (1) patient does not use illicit drugs; (2) patient makes use of illicit drugs. Smoking: (1) non-smoker patient; (2) smoker. Type of Treatment: (1) supervised treatment; (2) self-administered treatment.

Figure 2. Nomograms of deaths and bankruptcies in the treatment of multidrug-resistant tuberculosis. 
a score is computed, ranging from zero to 100. After considering all attributes, the patient's total score is added, which represents the probability of occurrence of the event in question. Thus, it is simplified the understanding of the prediction factor of these characteristics for the unfavorable outcome in the treatment of MDR-TB.

In the case of abandonment, considering the two variables included in the nomogram, a probability of $20 \%$ to $25 \%$ was observed for patients treated as MDR-TB virgin and approximately $20 \%$ for illicit drug users. Patients who belonged to both categories may present a $40 \%$ to $45 \%$ probability of dropping out of treatment.

Regarding death, patients on the first treatment of MDR-TB had approximately a $15 \%$ chance of death. Those who were diagnosed in emergency services or with elucidation of the case during hospital stay had between $15 \%$ and $20 \%$ chance. In the case of illicit drug use, the chance was $10 \%$ to $15 \%$. Combining these factors, the chance for this unfavorable outcome reached the range of $45 \%$ to $50 \%$.

Regarding treatment failure, the only variable with significant association was the number of previous treatments. For those in the first treatment for MDR-TB, there was little more than a $50 \%$ likelihood for failure outcome.

\section{DISCUSSION}

The study identified the main risk factors related to death, abandonment and treatment failure in MDR-TB treatments, with evidence of association of these outcomes with illicit drug use, number of previous MDR-TB treatments and place of diagnosis of the case. In addition, the predictive capacity for each of these variables was verified, allowing the identification of individuals at greater risk for unfavorable outcomes.

The results showed that in the state of São Paulo there was a growth in the proportion of patients' cure and a trend to reduce treatment failure, highlighting a visible conversion of these outcomes mainly from 2011, something also observed by Valdes et al. ${ }^{10}$. These trends are presumed to be related to the application of norms for diagnosis and treatment published in 2007, which allowed over time to reverse the state scenario of MDR-TB treatment observed between the 2006 and 2010 and to incorporate new drugs and regimens treatment in the state ${ }^{11}$. In addition, health teams have possibly accumulated experience and knowledge about the disease and care of these patients to the point of improve the outcome of cases. However, it is important to note that the proportion of cures in 2015, when the highest value (59.38\%) of the study period was observed, falls short of the goals established by WHO.

Regarding the outcomes of treatment abandonment and death with TB, both showed stationary trends, indicating that they are still key elements for the control of unfavorable outcomes of MDR-TB. Thus, it is important to strengthen both TB control programs and health services in the management and follow-up of these patients, especially considering that the reasons for patients discontinuing treatment and developing more severe forms of the disease are usually related to psychosocial factors.

Retreatment of MDR-TB was presented as a protective factor for outcomes, an unexpected result. A study by Bastos et al. ${ }^{12}$ in Brazil identified that the episode of resistant TB being the first in the patient's life resulted in higher chances of a positive outcome. Possibly, the divergence of these results with this study is in the agglutination of cases with mono and multiresistance in the same study population and in the fact that the Brazilian Southeast presents the worst results for cure, being able to represent a specific and distinct cohort of the rest of the country.

In addition, in China ${ }^{13}$ and Pakistan ${ }^{14}$ studies, there was a tendency for patients with previous unfavorable outcomes to have a lower chance of repeating them, even though such 
outcomes have not been significantly demonstrated in multivariate analyzes. In addition, failure to complete the "entry-type" field on the patient notification form on TBWeb made it impossible to identify whether patients who underwent new MDR-TB treatments did so due to abandonment, treatment failure, or relapse.

Despite the need to cautiously observe the previous treatments for MDR-TB and its relation to the outcomes, there is a possible explanation for the higher success rate in individuals who have already undergone it. After the first treatment, patients are presumably assisted more effectively by the health services and their professionals, who, considering previous outcomes, carry out educational actions on the disease, advising on the importance of ending the treatment, in addition to providing psychosocial support to both the patient and family members ${ }^{15}$. It cannot be disregarded the effect that failure to achieve cure has on the perception of threat of death for the patient, which may influence self-regulation and motivation to end the therapeutic regimen ${ }^{15}$.

In addition, previously treated and negatively evolving patients should be examined more rigorously before starting new treatments as recommended by $\mathrm{PNCTB}^{6}$, identifying the profile of susceptibility to second-line drugs more effectively and listing drug combinations for MDR-TB with a lower chance of treatment failure ${ }^{16,17}$.

However, it is important to consider the repercussions of repeated treatments for patients and for the health system itself. Despite universal access to medication, therapy usually implies high costs of transportation and food, resulting in loss of family income and catastrophic expenses ${ }^{18}$. For the health system, costs are also high, and the need for more than one treatment for therapeutic success can significantly burden public administration ${ }^{19}$. In addition, there are several sequelae of MDR-TB treatment, which can be aggravated by multiple therapeutic cycles. Some studies indicate that $90 \%$ of the treated cases present some sequelae, the most common being pulmonary dysfunctions such as dyspnea and reduced vital capacity, hearing loss due to ototoxicity, loss of quality of life and social isolation ${ }^{20}$.

Another risk factor specifically related to dropout and death from MDR-TB was the use of illicit drugs. This evidence has already been presented in other studies, both for cases of sensitive $\mathrm{TB}^{21}$ and for the resistant form of the disease ${ }^{22}$. It should be noted that illicit drug users are considered patients of great complexity, both due to the difficulty in preventing infection and developing the active form of the disease, as well as the comorbidities commonly associated with cases such as hepatitis B, hepatitis C and or HIV ${ }^{23}$. Such a population is afflicted by a high burden of stigma of TB, of illegal drug use and of a chance of an illicit lifestyle, as reported by Hayashi et al. ${ }^{24}$. These authors identified that $80 \%$ of injecting drug users had already been incarcerated in prisons at least once. As a consequence, they move away from the care provided by health professionals, and adherence to treatment is compromised to the point that services are unable to reach contact and bond ${ }^{25}$.

Based on these considerations and the results presented in the nomogram, it can be hypothesized that approximately half of the illicit drug users who are on the first MDR-TB treatment will abandon it and one-fourth may become fatal. Thus, for MDR-TB treatment of illicit drug users to have better results, it is necessary that specific measures are developed to ensure their full care ${ }^{22}$.

The health service in which the diagnosis was made showed an association with death due to MDR-TB. Patients whose case was elucidated in emergency services in the hospital network showed more than double the chance of death due to the disease.

Although primary health care (PHC) is recognized as the preferred entry point and structuring axis of the health system and is considered a priority for the control and care of patients with $\mathrm{TB}^{26}$, more than $25 \%$ of MDR-TB cases in the state of São Paulo were diagnosed in other types of services, evidencing the difficulty of PHC in carrying out the timely diagnosis of the disease. The reasons for the population to seek other ports of entry may be 
related to the difficulty of access to PHC, both due to the restricted hours of operation of the units and the low coverage of attention, and the cultural habit of seeking emergency units ${ }^{27}$.

The effects of delayed diagnosis may be extensive, as it results in a greater chance of MDR-TB transmission in the population, of patient suffering and of disease progression, which impairs the treatment outcome and increases the risk of death ${ }^{28}$. In this way, it is necessary to strengthen the actions to search for cases in the community and overcome old-fashioned system policies, expand and consolidate PHC coverage in municipalities, and invest in qualified professionals prepared to find cases appropriately ${ }^{29}$.

The construction of a prognostic model such as the nomogram can mean better therapeutic results and reduction of deaths, dropouts and failures in the treatment of MDR-TB. The nomogram tool is often used in the oncology area and considered simple and effective for a better prognosis of diseases ${ }^{30}$. One of its main advantages is the ability to individually estimate patients' risk based on their own characteristics, helping in decision making.

Considering the discrimination capacity of the logistic models of this study, it is possible to state that the nomogram presented has the capacity to predict the occurrence of abandonment, death and treatment failure in $65 \%, 70 \%$ and $80 \%$ of the cases, respectively. However, it is important to understand that these results have internal validation in the studied cohort and that other scenarios require a validation process for the population under analysis.

The study has limitations related to its retrospective character, meaning the inability to control the data collected from the TBWeb information system. In addition, the data may suffer from underreporting, mainly due to the diagnostic difficulty involved in MDR-TB, caused both by the lack of indication of patients to sensitivity tests and by the difficulty of access to technological equipment such as GeneXpert for all municipalities in the state of Sao Paulo.

\section{REFERENCES}

1. World Health Organization. Global tuberculosis report 2017. Geneva: WHO; 2017 [cited 2018 Jun 12]. Available from: https://www.who.int/tb/publications/global_report/gtbr2017_ main_text.pdf

2. Zumla A, Abubakar I. Clinical trial research in focus: overcoming barriers in MDR-TB clinical trials. Lancet Respir Med. 2017;5(4):247-8. https://doi.org/10.1016/S2213-2600(17)30091-7

3. World Health Organization. The shorter MDR-TB regimen. Geneva: WHO; 2016 [cited 2018 Jul 19]. Available from: https://www.who.int/tb/Short_MDR_regimen_factsheet.pdf

4. Walker IF, Baral SC, Wei X, Huque R, Khan A, Walley J, et al. Multidrug-resistant tuberculosis treatment programmes insufficiently consider comorbid mental disorders. Int J Tuberc Lung Dis. 2017;21(6):603-9. https://doi.org/10.5588/ijtld.17.0135

5. Sharma A, Hill A, Kurbatova E, Walt M, Kvasnovsky C, Tupasi TE, et al. Estimating the future burden of multidrug-resistant and extensively drug-resistant tuberculosis in India, the Philippines, Russia, and South Africa: a mathematical modelling study. Lancet Infect Dis. 2017;17(7):707-15. https://doi.org/10.1016/S1473-3099(17)30247-5

6. Ministério da Saúde (BR), Secretaria de Vigilância em Saúde, Departamento de Vigilância Epidemiológica. Manual de recomendações para o controle da tuberculose no Brasil. Brasília, DF; 2011 [cited 2018 Jul 16]. (Série A. Normas e Manuais Técnicos). Available from: http:// bvsms.saude.gov.br/bvs/publicacoes/manual_recomendacoes_controle_tuberculose_brasil.pdf

7. Antunes JLF, Cardoso MRA. Uso da análise de séries temporais em estudos epidemiológicos. Epidemiol Serv Saude. 2015;24(3):565-76. https://doi.org/10.5123/S1679-49742015000300024

8. Šimundi AM. Measures of diagnostic accuracy: basic definitions. EJIFCC. 2009 [cited 2018 Jun 21].;19(4):203-11. Available from: https://www.ncbi.nlm.nih.gov/pmc/articles/PMC4975285/

9. Balachandran VP, Gonen M, Smith JJ, DeMatteo RP. Nomograms in oncology: more than meets the eye. Lancet Oncol. 2015;16(4):e173-80. https://doi.org/10.1016/S1470-2045(14)71116-7 
10. Bollela VR, Puga FG, Moya MJ, Andrea M, Oliveira MLV. A decade trend of multidrug resistant tuberculosis in São Paulo State, Brazil. Rev Inst Med Trop Sao Paulo. 2016;58:77. https://doi.org/10.1590/S1678-9946201658077

11. Ministério da Saúde (BR), Secretaria de Vigilância em Saúde, Centro de Referência Professor Hélio Fraga. Tuberculose multirresistente: guia de vigilância epidemiológica Rio de Janeiro; 2007 [cited 2018 Jul 16]. Available from: http://www5.ensp.fiocruz.br/biblioteca/dados/ txt_670024370.pdf3

12. Bastos ML, Cosme LB, Fregona G, Prado TN, Bertolde AI, Zandonade E, et al. Treatment outcomes of MDR-tuberculosis patients in Brazil: a retrospective cohort analysis. BMC Infect Dis. 2017;17(1):718. https://doi.org/10.1186/s12879-017-2810-1

13. Alene KA, Yi H, Viney K, McBryde ES, Yang K, Bai L, et al. Treatment outcomes of patients with multidrug-resistant and extensively drug resistant tuberculosis in Hunan Province, China. BMC Infect Dis; 2017;17(1):573. https://doi.org/10.1186/s12879-017-2662-8

14. Atif M, Bashir A, Ahmad N, Fatima RK, Saba S, Scahill S. Predictors of unsuccessful interim treatment outcomes of multidrug resistant tuberculosis patients. BMC Infect Dis. 2017;17(1):655. https://doi.org/10.1186/s12879-017-2746-5

15. Deshmukh RD, Dhande DJ, Sachdeva KS, Sreenivas AN, Kumar AMV, Parmar M. Social support a key factor for adherence to multidrug-resistant tuberculosis treatment. Indian J Tuberc. 2018;65(1):41-7. https://doi.org/10.1016/j.ijtb.2017.05.003

16. Zhang L, Meng Q, Chen S, Zhang M, Chen B, Wu B, et al. Treatment outcomes of multidrugresistant tuberculosis patients in Zhejiang, China, 2009-2013. Clin Microbiol Infect. 2018;24(4):381-8. https://doi.org/10.1016/j.cmi.2017.07.008

17. Mitnick CD, White RA, Lu C, Rodriguez CA, Bayona J, Becerra MC, et al. Multidrug-resistant tuberculosis treatment failure detection depends on monitoring interval and microbiological method. Tuberc Respir J. 2016;48(4):1160-70. https://doi.org/10.1183/13993003.00462-2016

18. Ayé R, Wyss K, Abdualimova H, Saidaliev S. Household costs of illness during different phases of tuberculosis treatment in Central Asia: a patient survey in Tajikistan. BMC Public Health. 2010;10(1):18. https://doi.org/10.1186/1471-2458-10-18.

19. Marks SM, Flood J, Seaworth B, Hirsch-Moverman Y, Armstrong L, Mase S, et al. Treatment practices, outcomes, and costs of multidrug-resistant and extensively drugresistant tuberculosis, United States, 2005-2007. Emerg Infect Dis. 2014;20(5):812-21. https://doi.org/10.3201/eid2005.131037

20. Heysell SK, Ahmed S, Rahman MT, Akhanda MW, Gleason AT, Ebers A, et al. Hearing loss with kanamycin treatment for multidrug-resistant tuberculosis in Bangladesh. Eur Respir J. 2018;51(3):1701778. https://doi.org/10.1183/13993003.01778-2017

21. Lackey B, Seas C, Van der Stuyft P, Otero L. Patient characteristics associated with tuberculosis treatment default: a cohort study in a high-incidence area of Lima, Peru. PLoS One. 2015;10(6):e0128541. https://doi.org/10.1371/journal.pone.0128541

22. Cavanaugh JS, Kazennyy BY, Nguyen ML, Kiryanova E V, Vitek E, Khorosheva TM, et al. Outcomes and follow-up of patients treated for multidrug-resistant tuberculosis in Orel, Russia, 2002-2005. Int J Tuberc Lung Dis. 2012;16(8):1069-74. https://doi.org/10.5588/ijtld.11.0696

23. Getahun H, Gunneberg C, Sculier D, Verster A, Raviglione M. Tuberculosis and HIV in people who inject drugs: evidence for action for tuberculosis, HIV position an harm reduction services. Curr Opin HIV AIDS. 2012;7(4):345-53. https://doi.org/10.1097/COH.0b013e328354bd44

24. Hayashi K, Milloy MJ, Fairbairn N, Kaplan K, Suwannawong P, Lai C, et al. Incarceration experiences among a community-recruited sample of injection drug users in Bangkok, Thailand. BMC Public Health. 2009;9:492. https://doi.org/10.1186/1471-2458-9-492

25. Getahun H, Baddeley A, Raviglione M. Managing tuberculosis in people who use and inject illicit drugs. Bull World Health Organ. 2013;91(2):154-6. https://doi.org/10.2471/BLT.13.117267

26. Ministério da Saúde (BR), Departamento de Apoio à Descentralização, Coordenação-Geral de Apoio à Gestão Descentralizada. Diretrizes operacionais dos Pactos pela vida, em defesa do SUS e de gestão. Brasília, DF; 2006 [cited 2018 Jul 31]. (Série A. Normas e Manuais Ténicos) (Pactos pela Saúde 2006; 1). Available from: http://www.saude.mppr.mp.br/arquivos/File/ volume1.pdf 
27. Oliveira LH, Mattos RA, Souza AIS. Cidadãos peregrinos: os "usuários" do SUS e os significados de sua demanda a prontos-socorros e hospitais no contexto de um processo de reorientação do modelo assistencial. Cienc Saude Coletiva. 2009;14(5):1929-38. https://doi.org/10.1590/S1413-81232009000500035

28. Rifat M, Rusen ID, Islam MA, Enarson DA, Ahmed F, Ahmed SM, et al. Why are tuberculosis patients not treated earlier? A study of informal health practitioners in Bangladesh. Int J Tuberc Lung Dis. 2011;15(5):647-51. https://doi.org/10.5588/ijtld.10.0205

29. Ponce MAZ, Wysocki AD, Scatolin BE, Andrade RLP, Arakawa T, Ruffino Netto A, et al. Diagnóstico da tuberculose: desempenho do primeiro serviço de saúde procurado em São José do Rio Preto, São Paulo, Brasil. Cad Saude Publica. 2013;29(5):945-54. https://doi.org/10.1590/S0102-311X2013000500012

30. Grimes DA. The nomogram epidemic: resurgence of a medical relic. Ann Intern Med. 2008;149(4):273-5. https://doi.org/10.7326/0003-4819-149-4-200808190-00010

Funding: São Paulo Research Foundation (FAPESP - Process 2017/11040-4).

Authors' Contributions: Conception, study planning, data collection, data analysis and interpretation, and public responsibility for the content of the article: LHA. Elaboration and review of the manuscript: ACVM, MY, TZB, LSA, AZB, DTS, JDA, LTC, MAMA, VRB, SB. Analysis, interpretation and elaboration of the manuscript: CN. Design, planning, analysis, interpretation and approval of the final version of the manuscript: RAA.

Conflict of Interest: The authors declare no conflicts of interest. 